\title{
Prevention and treatment of rheumatic heart disease in the developing world
}

\author{
Andrew C. Steer and Jonathan R. Carapetis
}

\begin{abstract}
The prevalence of rheumatic heart disease (RHD) in industrialized countries has declined dramatically over the last century, but the disease remains an important global health problem with the burden of disease shouldered by developing countries. Indeed, data from epidemiologic surveys, which used echocardiography as the primary screening tool, indicate that the prevalence of RHD in developing nations might have been substantially underestimated. Despite the high burden of disease globally, there has never been a sustained and comprehensive international strategy to control RHD. The current focus of global efforts to combat the disease is on strengthening secondary prophylaxis strategies, although very few active national programs have been implemented. RHD will continue to cause high morbidity and mortality among the world's poorest populations unless current prevention initiatives expand and new programs are established.
\end{abstract}

Steer, A. C. \& Carapetis, J. R. Nat. Rev. Cardiol. 6, 689-698 (2009); published online 15 September 2009; doi:10.1038/nrcardio.2009.162

\section{Introduction}

The incidence and prevalence of acute rheumatic fever (ARF) and rheumatic heart disease (RHD) in the industrialized world have steadily decreased since the beginning of the twentieth century. In the early part of the last century, the incidence of ARF in many areas of the US was over 200 cases per 100,000 in children aged 5-15 years, and many hospitals had entire wards devoted to children with ARF. ${ }^{1}$ Today, clinicians in industrialized countries can expect to encounter only a single case of ARF during their career. Only 503 hospitalizations for ARF were reported in a study of more than 2.5 million hospital discharges from 2,784 institutions in 27 US states during 2000. ${ }^{2}$ However, ARF and RHD remain major health issues in most low-income and many middle-income countries. In this Review, we describe the pathophysiology and epidemiology of these conditions, as well as current and future approaches to their prevention and treatment.

\section{Definitions and pathophysiology}

ARF is an immune-mediated, multisystem inflammatory disease that follows group A streptococcal infection. This condition is characterized by tissue inflammation that gives rise to typical clinical characteristics, including carditis, valvulitis, arthritis, chorea, erythema marginatum, and subcutaneous nodules. The long-term effects of ARF on all tissues, except the cardiac valves, are minimal. Carditis occurs in $30-80 \%$ of patients with ARF, and at least $60 \%$ of untreated patients develop chronic RHD. ${ }^{3-6}$

The exact pathogenic mechanisms of ARF and RHD are not clear. However, an interaction between a group A streptococcal strain with unknown ARF-causing

Competing interests

The authors declare no competing interests. characteristics (not all group A streptococci have been causally associated with ARF) and a host with inherited susceptibility (the nature of which is also unclear) seems to lead to an abnormal immune response and the development of autoimmunity. ${ }^{7}$ Both cross-reactive antibodies and cross-reactive $\mathrm{T}$ cells are believed to have a role in the disease. Molecular mimicry between group A streptococcal antigens and human host tissue is thought to be the basis of this cross-reactivity. ${ }^{8}$ This mechanism has been best documented with $\alpha$-helical cardiac proteins, such as myosin, laminin, and vimentin. ${ }^{9}$ Several putative cross-reactive epitopes are expressed on group A streptococci including, among others, M-protein and N-acetyl glucosamine. ${ }^{9}$ Inflammation leads to neovascularization, which enables further recruitment of T cells, leading to granulomatous inflammation and the establishment of chronic RHD. ${ }^{10}$ Repeated episodes of ARF lead to further inflammatory damage and subsequent scarring of cardiac valves. The aim of secondary penicillin prophylaxis is to prevent worsening RHD by reducing the incidence of recurrent ARF. ${ }^{10}$

Traditionally, ARF was thought to follow group A streptococcal pharyngitis, but not group A streptococcal impetigo. ${ }^{11}$ However, some research has indicated that strains of group A streptococci commonly found on the skin could have a role in the pathogenesis of ARF-potentially by an immune-priming mechanism, or by movement of strains from skin to throat, although this evidence is not conclusive. ${ }^{12-14}$ Confirmation of this hypothesis would necessitate a reappraisal of primary prevention strategies, because primary prevention currently focuses only on treatment of group A streptococcal pharyngitis and not impetigo.

RHD predominantly affects the mitral valve and, less commonly, the aortic valve. Mitral valve incompetence
Centre for International Child Health, University of Melbourne, Parkville, Vic, Australia

(A. C. Steer). Menzies School of Health Research, Charles Darwin University, Darwin, NT, Australia (J. R. Carapetis).

Correspondence: A. C. Steer, Centre for International Child

Health, Department of Paediatrics, University of Melbourne, Royal

Children's Hospital,

Flemington Road, Parkville, Vic 3052, Australia andrew.steer@ rch.org.au 


\section{Key points}

- Rheumatic heart disease refers to the chronic cardiac sequelae that follow acute rheumatic fever-a multisystem, autoimmune disease caused by group A streptococcal infection

- Rheumatic heart disease is a substantial global health problem that predominantly occurs in developing countries

- Primary prophylaxis for rheumatic heart disease is effective on the individual level

- The current focus of global efforts to combat rheumatic heart disease is on strengthening secondary prophylaxis programs

- A group A streptococcal vaccine could be the ultimate means of preventing rheumatic heart disease in the long-term, but availability of a safe and effective vaccine is several years away

- Rheumatic heart disease will continue to be a global problem unless current prevention initiatives are expanded and sustained

is the most common valvular lesion in patients with RHD, particularly in the early stages of the disease. Mitral stenosis develops later as a result of persistent or recurrent valvulitis, although rapid progression to mitral stenosis has been described in some developing countries. ${ }^{5,15-17}$ Patients with mitral incompetence can remain relatively asymptomatic for up to 10 years, as a result of compensatory left atrial and left ventricular dilatation before the onset of left ventricular systolic dysfunction. ${ }^{18}$ Tricuspid regurgitation can occur as a result of volume overload, usually caused by mitral stenosis.

\section{RHD in developing countries}

When ARF was initially described, in 1931, it was believed to be a disease of temperate countries that was exceedingly rare in tropical zones. ${ }^{19}$ However, determining whether this belief was well founded is difficult because of a lack of data from developing countries in the first half of the twentieth century. What is clear is that ARF and RHD are currently important causes of acquired heart disease in developing countries. A review of the global burden of RHD published in 2005 estimated that $80 \%$ of the 15.6 million cases of RHD worldwide were in developing countries. ${ }^{20}$ The authors of this review also estimated that more than 200,000 new cases of RHD and 180,000 RHD-related deaths occur each year in the developing world. Theoretically, the predominance of ARF and RHD could have shifted from temperate to tropical regions in the last 50 years because of improvements in hygiene and sanitation in industrialized nations, followed by the rapid shift of populations into overcrowded urban areas in developing countries. ${ }^{21}$ The more likely explanation, however, is that ARF and RHD have been present at their current prevalence in tropical developing countries for a considerable period of time, but simply have not been documented.

The most reliable estimates of RHD prevalence are derived from formally conducted surveys, generally of school children aged between 5 and 18 years. ${ }^{22,23}$ Before the advent of echocardiography, these surveys were conducted by auscultation alone. Echocardiographic confirmation of clinical RHD provides more accurate assessments of prevalence. ${ }^{23}$ In a systematic review of studies that used echocardiographic confirmation of RHD detected by auscultation, the prevalence of clinically apparent RHD in children in developing countries was found to be between 1 and 3 cases per $1,000 .{ }^{23}$ The prevalence of RHD increases after childhood-peaking in adults aged 20-40 years-and the number of cases of RHD in school-aged children, therefore, represents less than $20 \%$ of the cases in the whole population. ${ }^{20}$

Regional variation is evident in the epidemiology of RHD, with a higher prevalence in Africa (5.7 cases per 1,000 school-aged children) and the Pacific region (Melanesia, Micronesia, Polynesia, plus indigenous Australians, the Maori, and Pacific Islanders in New Zealand; 3.5 cases per 1,000 school-aged children) than in other regions. ${ }^{20}$ Nonetheless, RHD is also an important cause of cardiovascular morbidity in the Middle East, Latin America, and Asia. ${ }^{20,24}$ Although good-quality data on ARF incidence are lacking for most of these regions, particularly for Africa, ${ }^{25}$ high rates of ARF have been reported, ${ }^{25}$ predominately in the Pacific region, ${ }^{5,26,27}$ including in indigenous populations of Australia and New Zealand. ${ }^{28,29}$

\section{Advances in epidemiology}

Two studies of school screening for RHD, performed in Mozambique and Cambodia between 2001 and 2005, used echocardiography as the primary screening tool. ${ }^{30}$ The prevalence of RHD detected by echocardiographic screening was 13 times greater than that detected by auscultatory screening in Mozambique (30.4 cases per $1,000$ vs 2.3 cases per 1,000$)$ and 10 times greater than for auscultation alone in Cambodia (21.5 cases per 1,000 vs 2.2 cases per 1,000$)$. Comparable results were found in Tonga, where a similar methodology was used (33.2 cases per 1,000 for echocardiography). ${ }^{31}$ In all three of these studies, the majority of lesions detected by echocardiography, but missed by auscultation, were mild. ${ }^{31}$ These studies have generated debate in the scientific community. ${ }^{32-34}$ On the one hand, detection of mild lesions is important because children with mild disease stand to benefit most from secondary prophylaxis. On the other hand, evaluation of the mitral valve by Doppler and twodimensional imaging is subtle and subjective, and potential for over-interpreting normal physiological changes exists, leading to incorrect diagnoses and overestimation of disease burden.

The question of whether mild changes on echocardiography truly represent subclinical RHD urgently requires an answer. The ideal approach to this issue would involve careful follow-up of patients with subclinical lesions to determine whether their disease evolves in a similar way to clinically apparent RHD, and whether secondary prophylaxis improves patient outcome. However, this type of study presents important ethical issues, given that children with good adherence to secondary prophylaxis would be compared with those who had poor adherence. In the absence of such a study, more definitive 
echocardiographic screening data from children at low risk of ARF and RHD are needed to determine the normal values for Doppler and two-dimensional valvular measurements. These normal ranges could then be applied to echocardiographic screening studies in highrisk populations, to easier distinguish children with pathological subclinical valve lesions from those who have normal levels of valvular regurgitation.

\section{Prevention and management of RHD}

The different approaches to prevention and management of RHD are summarized in Figure 1. Although established approaches to primary and secondary prevention of ARF exist, medical and surgical management of established RHD are the mainstay of efforts to reduce mortality in most countries, including in developing nations that can least afford these treatments. 'Preprimary' or 'primordial' prevention is another important consideration; evidence in support of primordial prevention comes partly from the observation that dramatic reductions in ARF and RHD in industrialized countries largely occurred before the introduction of penicillin. These reductions are thought to be the result of social change, such as improvements in hygiene and access to medical care, and reductions in overcrowding. ${ }^{1,35}$ A vaccine to prevent group A streptococcal infection could provide the greatest hope for curbing ARF and RHD in many developing countries.

\section{Primary prevention}

Studies from the 1940 s and 1950s, of US military recruits, clearly demonstrated that penicillin treatment for group A streptococcal pharyngitis can prevent ARF. ${ }^{36,37}$ This finding was supported by a meta-analysis that included ten trials conducted between 1950 and 1961, eight of which enrolled adults stationed on military bases in the US. ${ }^{38}$ The overall protective effect of antibiotics was impressive-reducing the risk of a patient with group A streptococcal pharyngitis from developing ARF by around $70 \%$ (relative risk [RR] 0.32, 95\% CI $0.21-0.48$ ). The number needed to treat to prevent one case of ARF was 53. Strategies to ensure that streptococcal pharyngitis is accurately diagnosed and appropriately treated ('primary prophylaxis') form the mainstay of recommendations for primary prevention from the WHO and other authorities. 22,39

Difficulties in implementing strategies for primary prophylaxis in developing countries have been acknowledged by the WHO. ${ }^{40}$ Most low-income countries have a shortage of skilled health-care personnel at the primarycare level and poor access to, or inability to afford, diagnostic facilities for taking and processing throat swabs. An effective primary prophylaxis strategy also relies on individuals attending a primary health-care center when they have a sore throat. Moreover, sufficient resources are vital for ensuring that patients can be treated once streptococcal pharyngitis is diagnosed, as is the assurance that recommended treatment regimens (oral penicillin

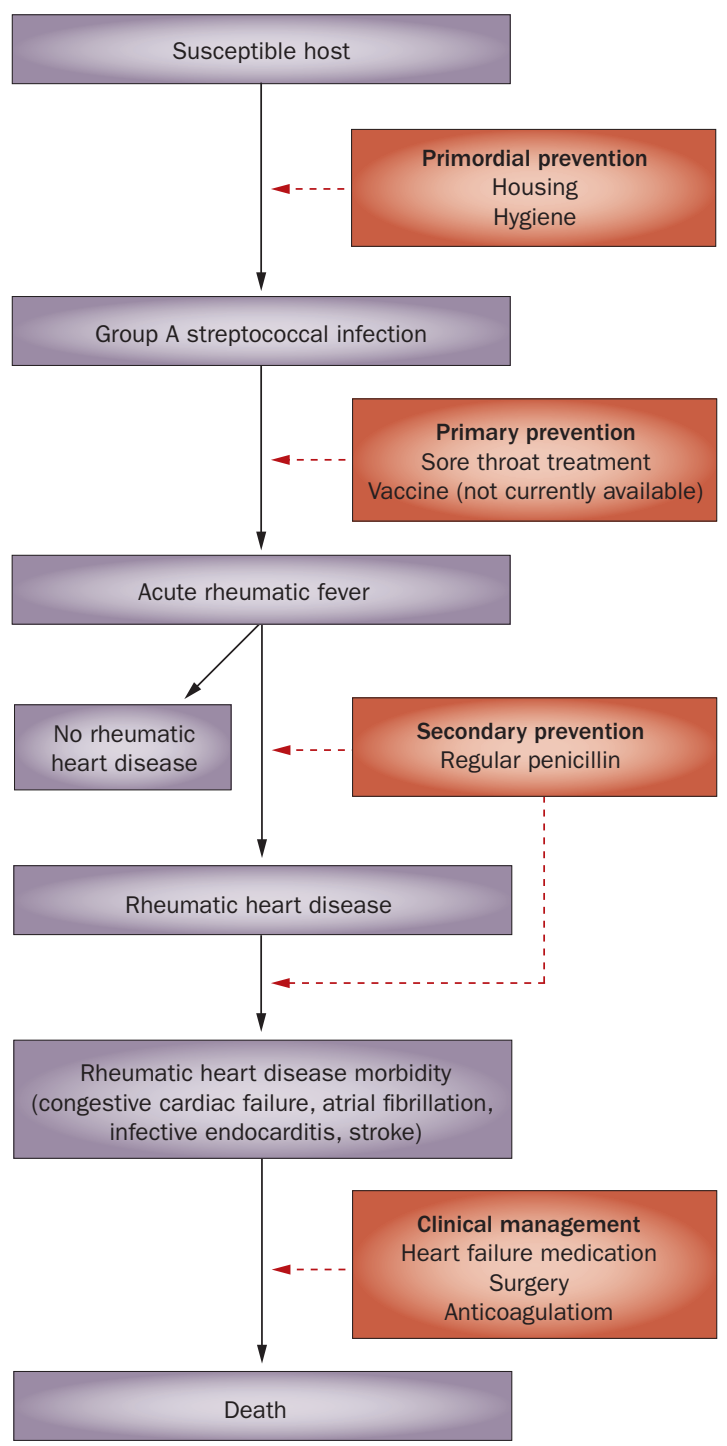

Figure 1 | Prevention and management strategies for acute rheumatic fever and rheumatic heart disease as they relate to pathogenesis. ${ }^{32}$

V $500 \mathrm{mg}$ 2-3 times per day for 10 days [ $250 \mathrm{mg}$ for children], $50 \mathrm{mg} / \mathrm{kg}$ amoxicillin per day for 10 days, or a single $1,200,000 \mathrm{U}[600,000 \mathrm{U}$ for children $\leq 27 \mathrm{~kg}]$ dose of intramuscular benzathine penicillin $\mathrm{G}$ ) will be adhered to. ${ }^{39,41}$ All of these requirements are difficult to achieve in low-income countries. Attempts have been made to validate clinical algorithms for the diagnosis of sore throat caused by group A streptococci, to remove at least one of the obstacles to effective primary prophylaxis, but as yet an algorithm of sufficient sensitivity and specificity has not been developed and implemented. ${ }^{42,43}$

Even in countries where adequate resources and a desire to implement effective primary-care-based primary prophylaxis are established, whether such an approach will, in itself, lead to a reduced incidence of ARF is unclear. ${ }^{44}$ Studies that reported the success of primary 
Table 1 | Costs of primary and secondary prevention, and valve surgery for RHD ${ }^{95}$

\begin{tabular}{lll}
\hline \multirow{2}{*}{ Intervention } & \multicolumn{2}{c}{ Cost per DALY averted (US\$) } \\
\cline { 2 - 3 } & Low-endemicity area & High-endemicity area \\
\hline Primary prevention & $68,346-102,520$ & $22,075-33,113$ \\
Secondary prevention & $982-1,103$ & $999-1,123$ \\
Valve surgery & 1,861 & 1,861 \\
\hline Vaccine* & $5,330-17,765$ & $137-458$ \\
\hline
\end{tabular}

*For low-endemicity area, assumes $80 \%$ efficacy and $90 \%$ coverage. For high-endemicity area, assumes $80 \%$ efficacy and 65-95\% coverage. Abbreviations: DALY, disability-adjusted life year; RHD, rheumatic heart disease. data in favor of community-based primary prophylaxis, they do not provide sufficient evidence to conclude that such a strategy leads to significant reductions in ARF incidence.

Perhaps most importantly for resource-poor settings, primary prophylaxis is the least cost-effective method for the prevention and management of RHD (Table 1). A single injection of benzathine penicillin $\mathrm{G}$ is inexpensive (approximately US\$0.75) and so, based upon the number needed to treat described in the meta-analysis by Lennon et al., ${ }^{48}$ preventing one case of ARF would theoretically cost only $\$ 40 .{ }^{38}$ However, the implementation and maintenance of primary prevention programs is laborintensive and expensive, and these programs are almost certainly not cost-neutral or cost-saving. For example, one program in Navajo children in the US could have resulted in a modest reduction in ARF incidence, but at a cost of $\$ 12$ per child enrolled per year, or $\$ 65,000$ per ARF case prevented..$^{50}$ By comparison, the total cost of an ARF case per year was estimated to be $\$ 10,560 .^{53}$ In high-income countries, this cost might be affordable (for example, rotavirus immunization costs $\$ 3,024$ per serious case averted, but routine meningococcal and pneumococcal immunization cost $\$ 633,000$ and $\$ 280,000$, respectively, to prevent one case of meningococcal disease or pneumococcal meningitis), ${ }^{54-56}$ but in low-income countries, these costs are prohibitive.

In our opinion, intensive sore throat surveillance and treatment programs cannot currently be recommended as coordinated public health programs in low-income and middle-income countries because this intervention has substantial cost implications for countries with the highest disease burden; in addition, the only randomized, controlled efficacy study did not demonstrate a significant treatment effect. Nonetheless, investigation and treatment of sore throat should continue to be promoted in settings where this strategy is feasible. Primary prophylaxis has the potential to prevent some cases of ARF and, therefore, has the advantage over secondary prophylaxis of preventing some cardiac damage that would otherwise occur. Moreover, educating health-care workers and the community about primary prophylaxis helps to raise general awareness about ARF and RHD and could have benefits that are not measurable simply in terms of effects on ARF incidence. ${ }^{43}$

\section{Secondary prevention}

Recurrent ARF leads to worsening of rheumatic valve lesions. ${ }^{6}$ As with primary prevention, early studies in the US proved the effectiveness of secondary prophylaxis with injectable benzathine penicillin $G$ for the prevention of recurrent ARF. ${ }^{57,58}$ In addition, secondary antibiotic prophylaxis has been shown to reduce the severity of $\mathrm{RHD}^{6,36,59}$ and is cost-effective. ${ }^{60}$

The ideal dose, route, frequency, and duration of administration for penicillin as secondary prophylaxis have not been established (particularly for children) and considerable variation is evident in practice and 
Table 2 | Recommendations for secondary prophylaxis of acute rheumatic fever

\begin{tabular}{|c|c|c|c|c|}
\hline Guidelines & $\begin{array}{l}\text { Dose of benzathine } \\
\text { penicillin } G\end{array}$ & Route & Interval & Duration \\
\hline $\mathrm{WHO}^{22}$ & $\begin{array}{l}\leq 30 \mathrm{~kg}: 600,000 \mathrm{U} ; \\
>30 \mathrm{~kg}: 1,200,000 \mathrm{U}\end{array}$ & PO acceptable & $21-28$ days & $\begin{array}{l}\text { No carditis: for } 5 \text { years or until } 18 \text { years of age*; } \\
\text { Resolved ARF carditis: for } 10 \text { years or until } \\
25 \text { years of age*; } \\
\text { Severe RHD, or if surgery is required: lifelong }\end{array}$ \\
\hline US $^{39}$ & $\begin{array}{l}\leq 27 \mathrm{~kg}: 600,000 \mathrm{U} ; \\
>27 \mathrm{~kg}: 1,200,000 \mathrm{U}\end{array}$ & $\begin{array}{l}\text { IM preferred; PO } \\
\text { acceptable if patient is } \\
\text { low-risk and has been } \\
\text { free of ARF attacks for } \\
5 \text { years or more }\end{array}$ & 28 days $^{\dagger}$ & $\begin{array}{l}\text { No carditis: for } 5 \text { years or until } 21 \text { years of age*; } \\
\text { Resolved ARF carditis: for } 10 \text { years or until } \\
21 \text { years of age*; } \\
\text { Severe RHD, or if surgery is required: for } \\
10 \text { years or until } 40 \text { years of age* (or longer) }\end{array}$ \\
\hline Australia ${ }^{77}$ & $\begin{array}{l}\leq 20 \mathrm{~kg}: 600,000 \mathrm{U} ; \\
>20 \mathrm{~kg}: 1,200,000 \mathrm{U}\end{array}$ & $\begin{array}{l}\text { IM preferred; PO } \\
\text { acceptable if } \\
\text { contra-indication to IM } \\
\text { or patient refusal }\end{array}$ & 28 days $^{\S}$ & $\begin{array}{l}\text { No carditis: for } 10 \text { years or until } 21 \text { years of age*; } \\
\text { Resolved ARF carditis: for } 10 \text { years or until } \\
21 \text { years of age*; } \\
\text { Moderate RHD: until } 35 \text { years of age; } \\
\text { Severe RHD: until } 40 \text { years of age (or longer) }\end{array}$ \\
\hline India ${ }^{78}$ & $\begin{array}{l}\leq 27 \mathrm{~kg}: 600,000 \mathrm{U} ; \\
>27 \mathrm{~kg}: 1,200,000 \mathrm{U}\end{array}$ & NA & $\begin{array}{l}\leq 27 \mathrm{~kg}: 15 \text { days; } \\
>27 \mathrm{~kg}: 21 \text { days }\end{array}$ & $\begin{array}{l}\text { No carditis: for } 5 \text { years or until } 18 \text { years of age*; } \\
\text { Resolved ARF carditis: for } 10 \text { years or until } \\
25 \text { years of age*; } \\
\text { Severe RHD, or if surgery is required: lifelong }\end{array}$ \\
\hline
\end{tabular}

in guidelines around the world (Table 2). ${ }^{22,39,61,62}$ A systematic review of randomized controlled trials revealed that intramuscular injection of benzathine penicillin $G$ every $2-4$ weeks is superior to daily oral penicillin. ${ }^{63}$ Lue et al. ${ }^{64,65}$ showed that benzathine penicillin $\mathrm{G}$ given every 3 weeks, rather than every 4 weeks, reduces the number of recurrences of ARF, although this finding was based on only a small amount of evidence. Currie and colleagues $^{66}$ reported that increased doses $(1,800,000 \mathrm{U}$ and 2,400,000 $\mathrm{U}$ ) of benzathine penicillin $\mathrm{G}$ provide protective levels of penicillin $(>25 \mathrm{ng} / \mathrm{ml})$ at 4 weeks after intramuscular injection in a greater proportion of patients than do standard doses (1,200,000 U). Not all practice reflects the available evidence, however, partly because of a lack of confidence in some of the data and partly because of the need for practicality, particularly in resource-limited settings. Maximizing adherence to treatment regimens is important and administering overly-frequent, large-volume doses of benzathine penicillin $G$ could potentially reduce adherence. ${ }^{67}$ The storage method and quality of benzathine penicillin $G$ can also affect serum levels of penicillin and the potential efficacy of this drug at preventing ARF. ${ }^{67,68}$ Very few data are available on the effect of the quality of benzathine penicillin $G$, although one study found that serum penicillin levels differed when benzathine penicillin $G$ was sourced from different manufacturers, despite the same dose being used. ${ }^{69}$

Secondary prevention has become synonymous with secondary prophylaxis, but a successful secondary prevention program encompasses more than just delivery of penicillin and should also include early recognition of ARF and RHD and strategies to increase adherence to antibiotic regimens. The essential elements of secondary prevention programs are summarized in Box $1 .{ }^{61}$ Health education and health promotion for health-care workers, patients and their families, and the general public are crucial for improving recognition of ARF and RHD. ${ }^{46}$ Coordination of secondary prevention and delivery of secondary prophylaxis as part of a centralized, registerbased program are important factors in achieving optimum levels of adherence. ${ }^{70}$ The effectiveness of secondary prevention is reduced by factors such as poor access to health services, limited educational opportunities, and poor environmental conditions, all of which are consequences of poverty. ${ }^{61}$ Importantly, register-based RHD secondary prevention programs have been successfully implemented and maintained over many years in a number of countries, including developing nations. ${ }^{44,70}$

Screening for RHD is another important facet of secondary prevention. The WHO recommends school-based screening for RHD to identify previously undiagnosed patients in high-prevalence regions. ${ }^{22}$ However, no agreement has yet been reached about the best approach to screening-which age group to screen and what combination of auscultation and echocardiography will provide sufficient sensitivity, specificity, cost-effectiveness, and feasibility in developing countries. A clear need exists to determine and standardize the best method for screening for RHD. ${ }^{32,33}$ Concerns also exist that screening on the scale described in the studies in Cambodia, Mozambique, ${ }^{30}$ and Tonga, ${ }^{31}$ will lead to the identification of a large number of cases that require ongoing clinical care and coordination, potentially overloading already stretched health systems.

Screening of school-aged children, together with the establishment of register-based control programs, formed the basis of the global program for RHD during the 1980s 
Box 1 | Secondary prophylaxis programs for RHD ${ }^{61}$

- RHD control programs should incorporate a single centralized (preferably computerized) ARF and RHD register, established within existing health-care networks, and linked to local registers in regions and individual communities. The register may be stand-alone, part of a more comprehensive chronic disease register, or housed within clinical departments or public health units. Registers should:

- maintain patient confidentiality

- conform to privacy legislation

- be established with the relevant institutional and and or individual approval

- Commitment from national, regional and local services, particularly to ensure long-term funding

- Activities guided by locally relevant, evidence-based guidelines

- A dedicated, centrally based coordinator

- A commitment to partnerships between clinicians and public health services in order to support the needs of people with ARF/RHD and the community

- An effective advisory committee that includes cardiologists, pediatricians, general practitioners, physicians, epidemiologists, nurses, public health practitioners, and relevant community representatives

- Prioritization of antibiotic prophylaxis delivered within the framework of primary health-care

- Planning and advocacy for a stable supply of benzathine penicillin, and establish plans for sustainable secondary prophylaxis in the event of supply reductions

- Ability to find new cases of ARF and RHD (including by screening programs)

- Ability to assess and monitor the burden of disease

- Provision of education for health practitioners, the community, those with disease and their families

- Legislated notification system of ARF and RHD which is supported by public health surveillance activities

- A priority system that ensures services are delivered to those at highest risk

- A mechanism for monitoring delivery of secondary prophylaxis and ongoing care, program reporting and independent evaluation

Abbreviations: ARF, acute rheumatic fever; RHD, rheumatic heart disease. Reproduced with permission from the National Heart Foundation of Australia; copyright material.

and 1990s. This initiative was conducted under the auspices of the WHO and the International Society and Federation of Cardiology, which subsequently became the World Heart Federation (WHF). ${ }^{71}$ The program demonstrated the feasibility of population-level approaches in a number of developing countries and had notable successes in case finding and improving adherence to secondary prophylaxis. ${ }^{72}$ However, chronic under-funding meant that few programs expanded beyond local or pilot examples, and the program was eventually abandoned. ${ }^{44}$ The lessons learned from the global program have been the basis for the current WHF approach to RHD control in developing countries. Well-resourced, register-based control programs and screening of school-aged children are established in demonstration sites, which are in turn used to promote expansion of the programs within the country and to neighboring countries. ${ }^{73}$ Promising developments have been achieved in the Pacific region and in sub-Saharan Africa with the WHF approach, but the sustainability of large-scale programs will depend on commitment from governments and funding agencies.

\section{Group A streptococcal vaccines}

The complexity of an effective population-level approach to primary prevention means that a group A streptococcal vaccine is clearly needed. ${ }^{74,75}$ An effective vaccine would prevent ARF and RHD by preventing the antecedent infection. There is a long history of attempts to develop such a vaccine; thus far most efforts have focused on the variable region of the $\mathrm{M}$ protein of the group $\mathrm{A}$ streptococcus. ${ }^{74}$ Concerns that a vaccine could increase, rather than decrease, the risk of subsequent ARF were a major impediment to vaccine development during the 1970s and 1980s. ${ }^{76}$ However, modern molecular technologies have enabled the development of vaccines with less potential for inducing autoimmunity and improved protocols for monitoring adverse events, meaning that group A streptococcal vaccine development has regained pace in the last two decades. ${ }^{74,75}$

Phase II trials in adults of a multivalent M type specific vaccine have been completed, with evidence of safety and immunogenicity. ${ }^{77}$ However, because of apparently differing profiles of $\mathrm{M}$ types in developing countries and the demonstrated potential for the rapid emergence of new $\mathrm{M}$ types in highly-endemic settings, the effectiveness of $M$ type specific vaccines will be limited in these areas unless they reflect the local molecular epidemio$\operatorname{logy} .^{78-80} \mathrm{~A}$ vaccine utilizing an antigen (or antigens) that is highly conserved among all group A streptococci could be a more promising strategy for developing countries. Antigens in this category include streptococcal C5a peptidase, the group A streptococcal carbohydrate, fibronectin binding proteins, and the conserved region of the M protein. ${ }^{81-84}$ Vaccines against these antigens are in development, but none have yet reached clinical trials. Crucially, vaccines specifically targeted against ARF and RHD need to be tested in countries where these diseases are common. ${ }^{74,75} \mathrm{An}$ effective and widely available group A streptococcal vaccine is at least several years away. So, for the foreseeable future, secondary prevention remains the most effective measure for controlling ARF and RHD, and primary prevention remains the most important second-line strategy.

\section{Management of established RHD}

The management of patients with RHD is complex, and a full discussion of the intricacies of clinical care of RHD is beyond the scope of this Review. The intensity of medical and surgical management increases with the severity of valvular disease (Table 3) ${ }^{61}$ Structured care planning and routine review is crucial in the successful management of patients with RHD. In resource-limited settings this approach can be challenging and burdensome for both the patient and the health-care system. One example is the intensity of monitoring required for patients who receive anticoagulation therapy, either for atrial fibrillation or because they have prosthetic valves. Adequate monitoring to achieve therapeutic anticoagulation can be difficult because of cultural factors, population transience, distance from pathology services, or simply 
because international normalized ratio testing is not available. The consequences of inadequate monitoring can be catastrophic; in a follow-up study of Aboriginal Australians (a population with access to a higher level of clinical care than in most developing countries) who underwent cardiac valve replacement for RHD, the 5-year event-free survival rate was only $52 \%$, with high rates of thromboembolic and bleeding complications associated with poor adherence to and monitoring of anticoagulant medication. ${ }^{85}$ In a study of 232 young women who underwent valve replacement (75\% of whom had RHD) between 1972 and 1992 in Auckland, New Zealand, $19.4 \%$ of women died and $25.9 \%$ had a thromboembolic event. ${ }^{86}$ Mortality at 10 years was highest in those with mechanical valve replacements (30\%, 95\% CI 17-41\%).

The choice of surgical procedure for patients with RHD is also critical. For example, when surgically feasible, the operation of choice for mitral incompetence is valvular repair rather than replacement because of lower procedural risk, better preservation of left ventricular function, the avoidance of long-term anticoagulation, and demonstrably better outcomes. ${ }^{87-89}$ However, success in this procedure relies to an extent on the surgeon's experience in performing it and must be balanced against a higher early reoperation rate than mitral valve replacement (up to $10 \%$ of patients develop mitral regurgitation within 2 years). ${ }^{87}$ The treatment of choice for symptomatic dominant or pure mitral stenosis is percutaneous balloon mitral valvuloplasty..$^{90,91}$ This procedure is comparable with surgical valvulopasty in terms of short-term and medium-term results, but it is less expensive and has a shorter postoperative recovery period. ${ }^{92,93}$ Like valvular repair for mitral incompetence, percutaneous valvuloplasty should be performed by a team experienced in the procedure. ${ }^{93}$ The restenosis rate is approximately $35 \%$ within 10 years. ${ }^{90,91}$ The best outcomes are achieved in younger patients because of favorable anatomy; however, in developing countries, patients with RHD often present late and with involvement of more than one valve. ${ }^{5,15,91}$ For these reasons, valvular repair or percutaneous balloon mitral valvuloplasty might not be available or feasible in most developing countries, even though these are the preferable procedures for many patients. Moreover, for many developing countries, cardiac surgery has to be performed at a specialist center overseas at considerable cost. The possibility that the patient will need a subsequent procedure can, therefore, be a disincentive for mitral valve repair or percutaneous valvuloplasty.

The most important aspects of the management of established RHD in developing countries are cost and cost-effectiveness. Unfortunately, medical or surgical care for people with severe RHD consumes the vast majority of funds available for RHD control in every country where this disease is an important health issue. Numerous examples exist of countries that allocate a considerable proportion of their entire health budgets (sometimes $5 \%$ or more) to RHD valve surgery. While
Table 3 | Management of patients with RHD, stratified by disease severity ${ }^{61}$

\begin{tabular}{|c|c|c|}
\hline Criteria & Management plan & Timing \\
\hline \multicolumn{3}{|l|}{ Low risk } \\
\hline \multirow{3}{*}{$\begin{array}{l}\text { ARF with no evidence } \\
\text { of RHD, or trivial to } \\
\text { mild valvular disease }\end{array}$} & Secondary prophylaxis (BPG) & Every 4 weeks \\
\hline & Doctor review & Annually \\
\hline & Echocardiography & $\begin{array}{l}\text { Children: every } 2 \text { years; } \\
\text { adults: every } 2-3 \text { years }\end{array}$ \\
\hline \multicolumn{3}{|l|}{ Medium risk } \\
\hline \multirow{9}{*}{$\begin{array}{l}\text { Any moderate valve } \\
\text { lesion in the absence } \\
\text { of symptoms and } \\
\text { with normal left } \\
\text { ventricular function, } \\
\text { or mechanical } \\
\text { prosthetic valves }\end{array}$} & Secondary prophylaxis (BPG) & Every 4 weeks \\
\hline & Doctor review & Every 6 months \\
\hline & Influenza vaccination & Annually \\
\hline & Electrocardiography (optional) & Annually \\
\hline & $\begin{array}{l}\text { Cardiologist, physician, and/or } \\
\text { pediatrician review }\end{array}$ & Annually \\
\hline & Echocardiography & Annually \\
\hline & Dental review & Annually \\
\hline & $\begin{array}{l}\text { Polysaccharide pneumococcal } \\
\text { vaccination }\end{array}$ & $\begin{array}{l}\text { Every } 5 \text { years } \\
\text { (maximum } 3 \text { doses) }\end{array}$ \\
\hline & Endocarditis prophylaxis & As required \\
\hline \multicolumn{3}{|l|}{ High risk } \\
\hline \multirow{9}{*}{$\begin{array}{l}\text { Severe valvular } \\
\text { disease, or moderate } \\
\text { to severe valvular } \\
\text { lesion with } \\
\text { symptoms, or tissue } \\
\text { prosthetic valves and } \\
\text { valve repairs }\end{array}$} & Secondary prophylaxis (BPG) & Every 3-4 weeks \\
\hline & Doctor review & Every 3-6 months \\
\hline & $\begin{array}{l}\text { Cardiologist/physician/ } \\
\text { pediatrician review }\end{array}$ & Every 3-6 months \\
\hline & Echocardiography & Every 3-6 months \\
\hline & Influenza vaccination & Annually \\
\hline & Dental review & $\begin{array}{l}\text { Within } 3 \text { months and annually } \\
\text { thereafter }\end{array}$ \\
\hline & $\begin{array}{l}\text { Polysaccharide pneumococcal } \\
\text { vaccination }\end{array}$ & $\begin{array}{l}\text { Every } 5 \text { years } \\
\text { (maximum } 3 \text { doses) }\end{array}$ \\
\hline & Endocarditis prophylaxis & As required \\
\hline & Warfarin plus aspirin & As prescribed \\
\hline
\end{tabular}

Abbreviations: ARF, acute rheumatic fever; BPG, benzathine penicillin G; RHD, rheumatic heart disease. Reproduced with permission from the National Heart Foundation of Australia; copyright material.

patients are transported thousands of kilometers to other countries where the surgery can be performed, the same country has no functioning secondary prophylaxis program, which could prevent most cases from progressing to severe RHD and save money. ${ }^{44,94}$ Although better and cheaper ways of treating patients with moderate or severe RHD are undoubtedly needed, ignoring the potential to prevent most of these cases in the first place by instituting effective, register-based control programs is a tragic waste of public-health resources. Secondary prevention is a cost-effective solution (Table 1) and must be a global priority.

\section{Conclusions}

RHD is an important global health problem, confined mainly to developing countries. Epidemiological prevalence surveys that used echocardiography as the primary screening tool indicate that the overall disease burden could be substantially higher than previously recognized. A comprehensive international strategy to control this disease has never existed, but attempts by the WHF, 
building on earlier approaches spearheaded by the WHO, hold promise. Although primary prophylaxis can work at an individual level, and increased promotion of the treatment of streptococcal sore throats in primary care is needed, no convincing data exist that the systematic implementation of such a strategy results in declines in ARF incidence. Moreover, the expense of systematic primary prophylaxis programs limits their feasibility in most developing nations where $\mathrm{ARF}$ and $\mathrm{RHD}$ are common. The current focus of global efforts to combat the disease is on strengthening secondary prophylaxis programs. Nevertheless, very few active national programs have been implemented. Secondary prevention programs face the harsh reality that communities with the highest rates of RHD are often those least equipped to deal with the problem. RHD will, therefore, remain unchecked among the world's poorest populations unless current prevention programs expand and new programs are established.

\section{Review criteria}

We reviewed our personal libraries of articles, compiled from previous comprehensive searches, and searched the Medline database by combining the terms "rheumatic fever" OR "rheumatic heart disease" and "developing country" to include articles published from June 1999 until June 2009 , with no limits set. We reviewed the abstracts and selected original and review articles that provided information relevant to diagnosis and management of rheumatic heart disease in developing countries.
1. Quinn, R. W. Comprehensive review of morbidity and mortality trends for rheumatic fever, streptococcal disease, and scarlet fever: the decline of rheumatic fever. Rev. Infect. Dis. 11, 928-953 (1989).

2. Miyake, C. Y., Gauvreau, K., Tani, L. Y., Sundel, R. P. \& Newburger, J. W. Characteristics of children discharged from hospitals in the United States in $\mathbf{2 0 0 0}$ with the diagnosis of acute rheumatic fever. Pediatrics 120, 503-508 (2007).

3. Sanyal, S. K., Berry, A. M., Duggal, S., Hooja, V. $\&$ Ghosh, S. Sequelae of the initial attack of acute rheumatic fever in children from north India: a prospective 5-year follow-up study. Circulation 65, 375-379 (1982).

4. Sanyal, S. K., Thapar, M. K., Ahmed, S. H., Hooja, V. \& Tewari, P. The initial attack of acute rheumatic fever during childhood in North India: a prospective study of the clinical profile. Circulation 49, 7-12 (1974).

5. Steer, A. C. et al. Acute rheumatic fever and rheumatic heart disease in Fiji: prospective surveillance, 2005-2007. Med. J. Aust. 190, 133-135 (2009).

6. Bland, E. F. \& Duckett-Jones, T. D. Rheumatic fever and rheumatic heart disease: a twenty year report on 1,000 patients followed since childhood. Circulation 4, 836-843 (1951).

7. Carapetis, J. R., Currie, B. J. \& Good, M. F. Towards understanding the pathogenesis of rheumatic fever. Scand. J. Rheumatol. 25 , 127-131 (1996).

8. Guilherme, L., Kalil, J. \& Cunningham, M. W. Molecular mimicry in the autoimmune pathogenesis of rheumatic heart disease. Autoimmunity 39, 31-39 (2006).

9. Vashishtha, A. \& Fischetti, V. A. Surfaceexposed conserved region of the streptococcal M protein induces antibodies cross-reactive with denatured forms of myosin. J. Immunol. 150, 4693-4701 (1993).

10. Veasy, L. G. \& Hill, H. R. Immunologic and clinical correlations in rheumatic fever and rheumatic heart disease. Pediatr. Infect. Dis. J. 16, 400-407 (1997).

11. Bisno, A. L., Pearce, I. A., Wall, H. P. Moody, M. D. \& Stollerman, G. H. Contrasting epidemiology of acute rheumatic fever and acute glomerulonephritis. N. Engl. J. Med. 283, 561-565 (1970).

12. McDonald, M., Currie, B. J. \& Carapetis, J. R. Acute rheumatic fever: a chink in the chain that links the heart to the throat? Lancet Infect. Dis. 4, 240-245 (2004).

13. McDonald, M. I. et al. Low rates of streptococcal pharyngitis and high rates of pyoderma in Australian aboriginal communities where acute rheumatic fever is hyperendemic. Clin. Infect. Dis. 43, 683-689 (2006).

14. Kaplan, E. L. \& Bisno, A. L. Antecedent streptococcal infection in acute rheumatic fever. Clin. Infect. Dis. 43, 690-692 (2006).

15. Singh, P. I. P. K., Carapetis, J. R., Buadromo, E. M., Samberkar, P. N. \& Steer, A. C. The high burden of rheumatic heart disease found on autopsy in Fiji. Cardiol. Young 18, 62-69 (2007).

16. Roy, S. B., Bhatia, M. L., Lazaro, E. J. \& Ramalingaswami, V. Juvenile mitral stenosis in India. Lancet 2, 1193-1195 (1963).

17. Knight, E. O., Kamdar, H. H. \& Chukwuemeka, A. Juvenile mitral stenosis in Kenya. East Afr. Med. J. 50, 476-479 (1973).

18. Marcus, R. H., Sareli, P., Pocock, W. A. \& Barlow, J. B. The spectrum of severe rheumatic mitral valve disease in a developing country: correlations among clinical presentation, surgical pathologic findings, and hemodynamic sequelae. Ann. Intern. Med. 120, 177-183 (1994).

19. Collis, W. R. Acute rheumatism and haemolytic streptococci. Lancet 217, 1341-1345 (1931)

20. Carapetis, J. R., Steer, A. C., Mulholland, E. K. $\&$ Weber, M. The global burden of group $A$ streptococcal diseases. Lancet Infect. Dis. 5, 685-694 (2005)

21. Wannamaker, L. W. Changes and changing concepts in the biology of group A streptococci and the epidemiology of streptococcal infections. Rev. Infect. Dis. 1, 967-975 (1979).

22. WHO. Rheumatic fever and rheumatic heart disease: report of a WHO Expert Consultation (WHO, Geneva, 2001).

23. Steer, A. C., Carapetis, J. R., Nolan, T. M. \& Shann, F. Systematic review of rheumatic heart disease prevalence in children in developing countries: the role of environmental factors. J. Paediatr. Child. Health 38, 229-234 (2002).

24. Carapetis, J. R. Rheumatic heart disease in Asia. Circulation 118, 2748-2753 (2008).

25. Tibazarwa, K. B., Volmink, J. A. \& Bongani, M. M. The incidence of acute rheumatic fever in the world: a systematic review of population-based studies. Heart 94, 1534-40 (2008).

26. Neutze, J. M. Rheumatic fever and rheumatic heart disease in the western Pacific region. N. Z. Med. J. 101, 404-406 (1988).
27. Chun, L. T., Reddy, D. V., Yim, G. K. \& Yamamoto, L. G. Acute rheumatic fever in Hawaii: 1966 to 1988. Hawaii Med. J. 51 , 206-211 (1992).

28. Carapetis, J. R., Wolff, D. R. \& Currie, B. J. Acute rheumatic fever and rheumatic heart disease in the Top End of Australia's Northern Territory. Med. J. Aust. 164, 146-149 (1996).

29. Jaine, R., Baker, M. \& Venugopal, K. Epidemiology of acute rheumatic fever in New Zealand 1996-2005. J. Paediatr. Child. Health 44, 564-571 (2008).

30. Marijon, E. et al. Prevalence of rheumatic heart disease detected by echocardiographic screening. N. Engl. J. Med. 357, 470-476 (2007).

31. Carapetis, J. R. et al. Evaluation of a screening protocol using auscultation and portable echocardiography to detect asymptomatic rheumatic heart disease in Tongan school children. Nat. Clin. Pract. Cardiovasc. Med. 5, 411-417 (2008)

32. Carapetis, J. R. Rheumatic heart disease in developing countries. N. Engl. J. Med. 357, 439-441 (2007).

33. Carapetis, J. R. Pediatric rheumatic heart disease in the developing world: echocardiographic versus clinical screening. Nat Clin. Pract. Cardiovasc. Med. 5, 74-75 (2008).

34. Marijon, E. et al. Echocardiographic screening for rheumatic heart disease. Bull. World Health Organ. 86, 84 (2008).

35. Gordis, L. Effectiveness of comprehensive-care programs in preventing rheumatic fever. N. Engl. J. Med. 289, 331-335 (1973).

36. Denny, F. W., Wannamaker, L. W., Brink, W. R., Rammelkamp, C. H. Jr \& Custer, E. A. Prevention of rheumatic fever: treatment of preceding streptococci infection. JAMA 143 151-153 (1950)

37. Chamovitz, R., Catanzaro, F. J., Stetson, C. A. \& Rammelkamp, C. H. Jr. Prevention of rheumatic fever by treatment of previous streptococcal infections. I. Evaluation of benzathine penicillin G. N. Engl. J. Med. 251, 466-471 (1954).

38. Robertson, K. A., Volmink, J. A. \& Mayosi, B. M. Antibiotics for the primary prevention of acute rheumatic fever: a meta-analysis. BMC Cardiovasc. Disord. 5, 11 (2005).

39. Gerber, M. A. et al. Prevention of rheumatic fever and diagnosis and treatment of acute streptococcal pharyngitis: a scientific statement from the American Heart Association Rheumatic 
Fever, Endocarditis, and Kawasaki Disease Committee of the Council on Cardiovascular Disease in the Young, the Interdisciplinary Council on Functional Genomics and Translational Biology, and the Interdisciplinary Council on Quality of Care and Outcomes Research: endorsed by the American Academy of Pediatrics. Circulation 119, 1541-1551 (2009).

40. [No authors listed] Strategy for controlling rheumatic fever/rheumatic heart disease, with emphasis on primary prevention: memorandum from a joint WHO/ISFC meeting. Bull. World Health Organ. 73, 583-587 (1995).

41. Lennon, D. R., Farrell, E., Martin, D. R. \& Stewart, J. M. Once-daily amoxicillin versus twice-daily penicillin $\mathrm{V}$ in group $\mathrm{A}$ betahaemolytic streptococcal pharyngitis. Arch. Dis. Child. 93, 474-478 (2008).

42. Mclsaac, W. J., Kellner, J. D., Aufricht, P., Vanjaka, A. \& Low, D. E. Empirical validation of guidelines for the management of pharyngitis in children and adults. JAMA 291, 1587-1595 (2004).

43. Steinhoff, M. C., Walker, C. F., Rimoin, A. W. \& Hamza, H. S. A clinical decision rule for management of streptococcal pharyngitis in low-resource settings. Acta Paediatr. 94, 1038-1042 (2005).

44. Carapetis, J. R. A review of WHO activities in, the burden of, and the evidence for strategies to control group A streptococcal diseases: Part 4: a review of the technical basis for the current WHO approach to the control of conditions associated with GAS infections (WHO, Geneva, 2004).

45. Arguedas, A. \& Mohs, E. Prevention of rheumatic fever in Costa Rica. J. Pediatr. 121 569-572 (1992).

46. Bach, J. F. et al. 10-year educational programme aimed at rheumatic fever in two French Caribbean islands. Lancet 347, 644-648 (1996).

47. Nordet, P., Lopez, R., Dueñas, A. \& Sarmiento, L. Prevention and control of rheumatic fever and rheumatic heart disease: the Cuban experience (1986-1996-2002). Cardiovasc. J. Afr. 19, 135-140 (2008)

48. Lennon, D., Kerdemelidis, M. \& Arroll, B. Metaanalysis of trials of streptococcal throat treatment programs to prevent rheumatic fever. Pediatr. Infect. Dis. J. 28, e259-e264 (2009).

49. Lennon, D. et al. Re-evaluation of a schoolbased primary prevention of acute rheumatic fever (ARF) randomised controlled trial (RCT): poised for action. Presented at the XVIth Lancefield International Symposium on Streptococci and Streptococcal Diseases.

50. Coulehan, J. L., Baacke, G., Welty, T. K. \& Goldtooth, N. L. Cost-benefit of a streptococca surveillance program among Navajo Indians. Public Health Rep. 97, 73-77 (1982).

51. Phibbs, B. et al. The Casper project-an enforced mass-culture streptococcic control program. J. Am. Med. Assoc. 166, 1113-1119 (1958).

52. Chun, L. T., Reddy, V. \& Rhoads, G. G. Occurrence and prevention of rheumatic fever among ethnic groups of Hawaii. Am. J. Dis. Child. 138, 476-478 (1984).

53. Thompkins, R. K., Butnes, D. C. \& Cable, W. E. An analysis of the cost-effectiveness of pharyngitis management and acute rheumatic fever prevention. Ann. Intern. Med. 86, 481-492 (1977).
54. Widdowson, M. A. et al. Cost-effectiveness and potential impact of rotavirus vaccination in the United States. Pediatrics 119, 684-697 (2007).

55. Shepard, C. W., Ortega-Sanchez, I. R., Scott, R. D. II \& Rosenstein, N. E. for the ABS Team. Cost-effectiveness of conjugate meningococcal vaccination strategies in the United States. Pediatrics 115, 1220-1232 (2005).

56. Lieu, T. A. et al. Projected cost-effectiveness of pneumococcal conjugate vaccination of healthy infants and young children. JAMA $\mathbf{2 8 3}$ 1460-1468 (2000)

57. Stollerman, G. H., Rusoff, J. H. \& Hirschfeld, I. Prophylaxis against group A streptococci in rheumatic fever; the use of single monthly injections of benzathine penicillin G. N. Engl. J. Med. 252, 787-792 (1955).

58. Tompkins, D. G., Boxerbaum, B. \& Liebman, J. Long-term prognosis of rheumatic fever patients receiving regular intramuscular benzathine penicillin. Circulation 45, 543-551 (1972)

59. Majeed, H. A., Batnager, S., Yousof, A. M., Khuffash, F. \& Yusuf, A. R. Acute rheumatic fever and the evolution of rheumatic heart disease: a prospective 12 year follow-up report. J. Clin. Epidemiol. 45, 871-875 (1992).

60. Strasser, T. Cost-effective control of rheumatic fever in the community. Health Policy 5 159-164 (1985).

61. National Heart Foundation of Australia (RF/RHD guideline development working group) and the Cardiac Society of Australia and New Zealand. Diagnosis and management of acute rheumatic fever and rheumatic heart disease in Australia-an evidence-based review. The Royal Australian College of General Practitioners [online], http://www.racgp.org.au/guidelines/ rheumaticfever (2006).

62. Saxena, A. et al. for the Working Group on Pediatric Acute Rheumatic Fever and Cardiology Chapter of Indian Academy of Pediatrics. Consensus guidelines on pediatric acute rheumatic fever and rheumatic heart disease. Indian Pediatr. 45, 565-573 (2008).

63. Manyemba, J. \& Mayosi, B. M. Penicillin for secondary prevention of rheumatic fever. Cochrane Database of Systematic Reviews, Issue 3, Art. No.: CD002227. doi:10.1002/14651858.CD002227 (2002).

64. Lue, H. C. et al. Rheumatic fever recurrences: controlled study of 3-week versus 4-week benzathine penicillin prevention programs. J. Pediatr. 108, 299-304 (1986).

65. Lue, H. C., Wu, M. H., Wang, J. K., Wu, F. F. $\& \mathrm{Wu}, \mathrm{Y} . \mathrm{N}$. Long-term outcome of patients with rheumatic fever receiving benzathine penicillin G. prophylaxis every three weeks versus every four weeks. J. Pediatr. 125 812-816 (1994).

66. Currie, B. J., Burt, T. \& Kaplan, E. L. Penicillin concentrations after increased doses of benzathine penicillin $\mathrm{G}$ for prevention of secondary rheumatic fever. Antimicrob. Agents Chemother. 38, 1203-1204 (1994).

67. Currie, B. J. Are the currently recommended doses of benzathine penicillin $\mathrm{G}$ adequate for secondary prophylaxis of rheumatic fever? Pediatrics 97, 989-991 (1996).

68. Kaplan, E. L. \& Johnson, D. R. Unexplained reduced microbiological efficacy of intramuscular benzathine penicillin $\mathrm{G}$. and of oral penicillin $\mathrm{V}$ in eradication of group $\mathrm{A}$ streptococci from children with acute pharyngitis. Pediatrics 108, 1180-1186 (2001)

69. Zaher, S. et al. Differences in serum penicillin concentrations following intramuscular injection of benzathine penicillin G (BPG) from different manufacturers. J. Pharm. Med. 2, 17-23 (1992).

70. McDonald, M., Brown, A., Noonan, S. \& Carapetis, J. R. Preventing rheumatic fever: the role of register-based programmes. Heart 91, 1131-1133 (2005).

71. WHO. WHO/ISFC/UNESCO joint project on RF/ RHD prevention and health promotion in schoolchildren: guidelines for the plan of operation for phase 1 (WHO, Geneva, 1995).

72. WHO. The WHO global programme for the prevention of rheumatic fever and rheumatic heart disease: report of a consultation to review progress and develop future activities (WHO, Geneva, 2000).

73. World Heart Federation. Rheumatic Heart Disease Network (RHDnet) [online], www.worldheart.org/rhd (2009).

74. Bisno, A. L., Rubin, F. A., Cleary, P. P. \& Dale, J. B. Prospects for a group A streptococcal vaccine: rationale, feasibility, and obstacles-report of a National Institute of Allergy and Infectious Diseases workshop. Clin. Infect. Dis. 41 1150-1156 (2005).

75. WHO Department of Child and Adolescent Health and Development; Department of Immunization, Vaccines and Biologicals. Group A streptococcal vaccine development: current status and issues of relevance to less developed countries (WHO, Geneva, 2005).

76. Massell, B. F., Honikman, L. H. \& Amezcua, J. Rheumatic fever following streptococcal vaccination: report of three cases. JAMA 207 , 1115-1119 (1969).

77. McNeil, S. A. et al. A double-blinded, randomized, controlled phase II trial of the safety and immunogenicity of a 26 valent group A streptococcus vaccine in healthy adults. Presented at the XVIth Lancefield International Symposium on Streptococci and Streptococcal Diseases.

78. Bessen, D. E. et al. Contrasting molecular epidemiology of group A streptococci causing tropical and nontropical infections of the skin and throat. J. Infect. Dis. 182, 1109-1116 (2000).

79. Steer, A. C. et al. Prospective surveillance of invasive group A streptococcal disease, Fiji, 2005-2007. Emerg. Infect. Dis. 15, 216-222 (2009)

80. Tewodros, W. \& Kronvall, G. M protein gene (emm type) analysis of group A beta-hemolytic streptococci from Ethiopia reveals unique patterns. J. Clin. Microbiol. 43, 4369-4376 (2005).

81. Sabharwal, H. et al. Group A streptococcus (GAS) carbohydrate as an immunogen for protection against GAS infection. J. Infect. Dis. 193, 129-135 (2006)

82. Shet, A., Kaplan, E. L., Johnson, D. R. \& Cleary, P. P. Immune response to group A streptococcal C5a peptidase in children: implications for vaccine development. J. Infect. Dis. 188, 809-817 (2003)

83. Batzloff, M. R. et al. Protection against group A streptococcus by immunization with J8-diptheria toxoid: contribution of J8- and diphtheria toxoidspecific antibodies to protection. J. Infect. Dis. 187, 1598-1608 (2003)

84. Batzloff, M., Yan, H., Davies, M., Hartas, J. \& Good, M. Preclinical evaluation of a vaccine 
based on conserved region of $\mathrm{M}$ protein that prevents group A streptococcal infection. Indian J. Med. Res. 119 (Suppl.), 104-107 (2004).

85. Carapetis, J. R. et al. Outcomes of cardiac valve replacement for rheumatic heart disease in Aboriginal Australians. Asia Pac. Heart J. 8 138-147 (1999).

86. North, R. A. et al. Long-term survival and valverelated complications in young women with cardiac valve replacements. Circulation 99 2669-2676 (1999).

87. Yau, T. M., El-Ghoneimi, Y. A., Armstrong, S., Ivanov, J. \& David, T. E. Mitral valve repair and replacement for rheumatic disease. J. Thorac. Cardiovasc. Surg. 119, 53-60 (2000).
88. Thourani, V. H. et al. Outcomes and long-term survival for patients undergoing mitral valve repair versus replacement: effect of age and concomitant coronary artery bypass grafting. Circulation 108, 298-304 (2003).

89. Enriquez-Sarano, M., Akins, C. W. \& Vahanian, A. Mitral regurgitation. Lancet 373, 1382-1394 (2009).

90. Hernandez, R. et al. Long-term clinical and echocardiographic follow-up after percutaneous mitral valvuloplasty with the Inoue balloon. Circulation 99, 1580-1586 (1999).

91. lung, B. et al. Late results of percutaneous mitral commissurotomy in a series of 1024 patients. Analysis of late clinical deterioration: frequency, anatomic findings, and predictive factors. Circulation 99, 3272-3278 (1999).

92. Reyes, V. P. et al. Percutaneous balloon valvuloplasty compared with open surgical commissurotomy for mitral stenosis. N. Engl. J. Med. 331, 961-967 (1994).

93. Carabello, B. A. Modern management of mitral stenosis. Circulation 112, 432-437 (2005).

94. Viali, S. Rheumatic fever and rheumatic heart disease in Samoa. Pac. Health Dialog. 13, 31-38 (2006).

95. Michaud, C., Rammohan, R. \& Narula, J. In Rheumatic Fever (eds Narula, J., Virmani, R., Reddy, K. S. \& Tandon, R.) 485-497 (American Registry of Pathology, Washington, D. C., 1999). 